\title{
Current perspectives on natural killer cell education and tolerance: emerging roles for inhibitory receptors
}

This article was published in the following Dove Press journal:

ImmunoTargets and Therapy

16 March 2015

Number of times this article has been viewed

\section{Michael Thomas}

Laboratory of Immunogenetics, National Institute of Allergy and Infectious Diseases, National Institutes of Health, Rockville, MD, USA
Correspondence: L Michael Thomas Laboratory of Immunogenetics, National Institute of Allergy and Infectious Diseases, National Institutes of Health, I244I Parklawn Drive, Rockville, MD 20852, USA

Tel + I 30| 496295 |

Fax +I 30I 4020259

Email louis.thomas@nih.gov
Abstract: Natural killer (NK) cells are regulated through the coordinated functions of activating and inhibitory receptors. These receptors can act during the initial engagement of an NK cell with a target cell, or in subsequent NK cell engagements to maintain tolerance. Notably, each individual possesses a sizable minority-population of NK cells that are devoid of inhibitory receptors that recognize the surrounding MHC class I (ie, self-MHC). Since these NK cells cannot perform conventional inhibition, they are rendered less responsive through the process of NK cell education (also known as licensing) in order to reduce the likelihood of auto-reactivity. This review will delineate current views on NK cell education, clarify various misconceptions about NK cell education, and, lastly, discuss the relevance of NK cell education in anti-cancer therapies.

Keywords: natural killer cell education, natural killer cell inhibitory receptors, immunotherapy, cancer

\section{Introduction}

Natural killer (NK) cells are finely tuned to their microenvironment, in particular the expression of MHC class I in their surroundings. ${ }^{1}$ MHC class I serves as a ligand for various inhibitory receptors that are expressed by NK cells. These inhibitory receptors include the killer cell immunoglobulin-like receptor (KIR), which are expressed by human NK cells, as well as the non-structurally homologous (yet functionally similar) Ly49 receptors, which are expressed by mouse NK cells. Of significance, the emergence of Ly49 along with KIR serves as a textbook example of convergent evolution and highlights the recent development and importance of inhibitory receptors and their regulation. ${ }^{2}$ Although often overlooked, NKG2A is included among the aforementioned inhibitory receptors and functions to recognize non-classical MHC class I HLA-E in humans and Qa-1 in mice respectively. In the context of a potential immune synapse, engaged inhibitory receptors signal to promote the activity of phosphatases such as SHP-1. ${ }^{3-6}$ Activation of these phosphatases down-modulates NK cell activation through de-phosphorylation of phosphotyrosines on target proteins such as Vav-1, ${ }^{7,8}$ which plays a central role in determining NK cell cytotoxicity. ${ }^{9}$ Additionally, NK cell inhibition actively signals for the activation of Abl kinase for phosphorylation of the adaptor molecule Crk. ${ }^{7,10}$ Crk has dual roles both in the activation and inhibition of NK cell responses, but the phosphorylation of Crk results in the destabilization of the actinreorganizing signaling scaffold of p130Cas, C3G and c-Cbl and may be a molecular mechanism that results in decreased immune cell activation including NK cells. ${ }^{11}$ submit your manuscript | www.dovepress.com
Dovepress

http://dx.doi.org/10.2147/1TT.S61498 


\section{Findings that led to the realization of NK cell education}

Paradoxically, although a sizeable minority of NK cells lack recognition of the surrounding MHC class I in mice and in humans, they are not hyper-functioning - in fact, they are hyporesponsive. ${ }^{12,13}$ How is it, then, that these NK cells are finely regulated so as to not overtly cause autoimmunity? A process known as NK cell education holds these NK cells in check. ${ }^{14}$ The principles of NK cell education have been an area of active research over the past decade; however, the foundation for NK cell education has been revealed through bits and pieces for much longer. In perhaps the first substantial observation, it was determined that NK cells from beta- 2 microglobulin knockout mice do not reject beta-2 microglobulin knockout mouse-derived grafts. ${ }^{15-18}$ Later, in the landmark paper that coined the phrase "NK cell licensing", it was demonstrated that functioning ITIM motifs in inhibitory receptors maintain optimal NK cell responsiveness. ${ }^{13}$ Shortly thereafter, the findings from mice were extended to humans with the observation that NK cells that express certain inhibitory receptors (KIR2DL1, KIR2DL2, KIR2DL3, KIR3DL1, and NKG2A) are generally more responsive than the NK cells that lack those particular inhibitory receptors; these findings are consistent with the principles set forth by NK cell education. ${ }^{12}$ Thus, over time, it has been revealed that, in addition to regulating NK cell function through conventional inhibition at immune synapses with target cells, inhibitory receptors, along with MHC class I, also condition NK cell responsiveness to subsequent encounters with target cells.

\section{NK cell education is quantitative}

Several groups have observed that NK cell education is quantitative. ${ }^{19-21} \mathrm{NK}$ cells with a greater number of inhibitory receptors that recognize the surrounding MHC class I respond to stimuli better than NK cells with less recognition of the surrounding MHC. Individuals with increasingly diverse repertoires of MHC class I molecules have a greater potential for their NK cells to be more responsive. In this sense, there are gradations of educated NK cells within individuals, with some subsets of NK cells being more educated than others. Furthermore, the strength of affinity of an inhibitory receptor to its cognate MHC class I ligand also dictates the degree of enhanced responsiveness. ${ }^{22}$

\section{The education status of an NK cell is altered with changes in NK cell inhibitory receptor expression}

In addition to being a quantitative process, NK cell education is a tunable process. ${ }^{23,24}$ In other words, individual
NK cells can change to become more responsive or less responsive through education. The altered responsiveness that is imparted through education can come through altered inhibitory receptor expression on the NK cell. Inhibitory receptor expression changes as NK cells mature throughout their development. ${ }^{25-27}$ The current hypothesis for human NK cell development is that young NK cells are CD56bright NK cells that express NKG2A.$^{28}$ CD56bright NK cells differentiate into CD56dim NK cells, which corresponds subsequently with a progressive loss of NKG2A and gain in KIR. As CD56dim NK cells age, they diversify their expression of KIR. Even though the expression of the acquired KIR is stochastic, ${ }^{29-32}$ NK cells balance KIR and NKG2A expression and regulate KIR copy number to enable greater potential for education irrespective of the surrounding MHC class I microenvironment. ${ }^{33-36}$ In addition to inhibitory receptor expression changing throughout NK cell maturation, prolonged mitogen IL-2 or IL-15 stimulation of NK cells results in gained expression of NKG2A and KIR. ${ }^{27,37}$ The newly expressed NKG2A and KIR from IL-2 or IL-15 treatment functions in both inhibition and education. ${ }^{38}$ Thus, it is possible that inflammatory situations such as those induced naturally by infections or artificially to enhance anti-tumor efficacy could result in acquired NK cell responsiveness through newly gained inhibitory receptor expression. Nevertheless, this phenomenon has not been thoroughly evaluated as of yet.

\section{NK cell education is reversible in response to changes in the surrounding MHC class I microenvironment}

In addition to changes in inhibitory receptor expression, NK cells can have their education status altered in response to changes in their surrounding MHC class I microenvironment. The impact of changing the surrounding MHC class I microenvironment on the functionality of mature mouse NK cells was first demonstrated in adoptive transfer studies..$^{23,24}$ The adoptive transfer of NK cells from MHC-competent mice to MHC-deficient mice resulted in a loss of NK cell functionality whereas the adoptive transfer of NK cells from MHC-deficient mice to MHC-competent mice resulted in a gain of NK cell functionality. The change of the NK cell's surrounding MHC class I may seem to be more of an artifact in experimental systems like an MHC class I deficient mouse; however, NK cell responsiveness decreases in response to tumor microenvironments that exhibit decreased MHC class I expression. ${ }^{39}$ On the other hand, inflammation can increase 
MHC class I expression, ${ }^{40}$ which may increase NK cell responsiveness through education. These concepts remain open areas of further research.

\section{Arming and disarming hypotheses}

It is commonly thought that NK cell education occurs through one of two mechanisms - either "arming" or "disarming". ${ }^{14}$ These hypotheses have been thoroughly examined in several past reviews. It is possible that both mechanisms regulate education in different contexts, or at the very least, that the two concepts are not mutually exclusive. ${ }^{41}$ In the context of persistent inflammation, such as might be the case with tumors, the constant barrage of stress activating ligands may overwhelm NK cells to an extent that renders them less responsive. The sustained presence of activating ligands in transgenic or chimeric mice results in NK cell hyporesponsiveness, ${ }^{42-44}$ but the decreased response in these mice is limited to the chronically engaged receptor, ${ }^{45}$ whereas education affects NK cell function globally. Receptor desensitization typically results in a loss of receptor expression, yet there is no evidence of decreased activating receptor expression on uneducated NK cells. It may be possible that intracellular signaling components are rendered less effective through the disarming hypothesis. Notably, NK cell-specific SHP-1 deletion resulted in globally hyporesponsive NK cells in one study and displayed surface receptor changes similar to uneducated NK cells. ${ }^{46}$ Additional studies are necessary though to see if there is misregulated SHP-1 in uneducated NK cells. The current burden of the arming hypothesis is to show that there is a proactive signaling pathway downstream of inhibitory receptors that enable better subsequent NK cell responsiveness. The phosphorylation of Abl kinase is a proactive target of inhibitory receptor signaling, ${ }^{7}$ but it remains to be addressed whether it has a role in promoting education. Conceptually, it is enticing to think that arming promotes education during NK cell development, when there is presumably a lack of surrounding inflammation.

\section{Proposed cell types that promote education}

It is currently disputed as to which cell types are important for presenting MHC class I in NK cell education, with some groups arguing for presentation by hematopoietic and others for presentation by non-hematopoietic cells. ${ }^{47}$ Another possibility exists as well, in which MHC class I on NK cells act in cis with inhibitory receptors to enable education. ${ }^{48}$ It is possible that each of these scenarios is biologically relevant and correct in different circumstances, given the differences in experimental set-up of the studies that described these mechanisms. It is enticing to speculate that non-hematopoietic cells could be important to maintain the education of NK cells during development, as these developing NK cells are also receiving survival cues through presented IL-15 from endothelial cells. ${ }^{47}$ Further, it is tempting to think that mature NK cells undergo continuing education by hematopoietic cells as both cell types reside in the blood. While it may be possible for murine Ly49 receptors on NK cells to act in cis with the same NK cell's MHC class I for mouse NK cell education, ${ }^{49}$ it has yet to be shown that a similar cis interaction could occur between human KIR or NKG2A and HLA molecules.

\section{Molecular mechanism of NK cell education}

Lastly, the molecular mechanism of NK cell education has not been extensively examined. The most prominent idea in the field is that a unique actin-meshwork restricts the movements of activating receptors in uneducated but not in educated NK cells. ${ }^{50}$ It remains unknown, however, whether restriction of activating receptors in uneducated NK cells actually results in decreased functionality of the cells. Furthermore, it has not been fully established whether educated NK cells lack this unique actin meshwork. Therefore, elucidating the molecular mechanism of NK cell education is an important area of active research.

\section{Misconceptions of NK cell education Uneducated NK cells can become activated}

While uneducated NK cells underperform in cytotoxicity and pro-inflammatory cytokine secretion relative to their more educated counterparts, uneducated NK cells are indeed capable of becoming activated. In fact, uneducated NK cells can perform better than educated NK cells in certain circumstances. For instance uneducated NK cells without inhibitory receptors lack inhibition when in contact with target cells that express MHC class I. Further, if MHC class I-expressing target cells are cancerous, then uneducated NK cells could prove to be beneficial towards their clearance. The uneducated NK cells could especially prove to be beneficial if provided with robust activating-receptor signals such as those achieved through the Fc receptor CD16. ${ }^{51}$ In potential clinical situations with antibody-dependent cellular cytotoxicity (ADCC) against certain lymphomas, uneducated but not educated NK cells eliminated MHC class I positive cancer cells. ${ }^{52}$ Uneducated NK cells also promote better mouse survival and 
viral clearance of MCMV. ${ }^{53}$ In a follow-up study, the situation may be more complicated in that somehow educated NK cells are more susceptible to the effects of suppressive T regulatory cells (Tregs). ${ }^{54}$ Regardless, uneducated NK cells can function in traditional NK cell roles and can out-do educated NK cells albeit only in certain contexts.

Not only are uneducated NK cells able to respond to activating stimuli, uneducated NK cells are actually not defective in all aspects of NK cell function. Most of the focus on NK cell activity in the context of NK cell education includes evaluation of the degranulation of lytic granules and intracellular expression of IFN-gamma. Such assays are fairly feasible through multi-parameter flow cytometry but do not address other aspects of cytotoxicity or actual secretion of multiple cytokines and chemokines let alone other non-traditional properties of NK cells. The full extent of NK cell-mediated cytotoxicity is a highly regulated process with multiple parameters. ${ }^{55}$ One such parameter that is an important aspect of NK cell cytotoxicity is NK cell lytic granule polarization. Lytic granule polarization is a complex orchestration of both microtubules and other cellular migration machinery such as GTPase Cdc42. ${ }^{56}$ Unlike lytic granule degranulation, NK cell education does not affect lytic granule polarization as the adhesion molecule LFA-1 function in promoting polarization is maintained. ${ }^{57}$ In fact, it appears that the greatest and perhaps only deficiency in uneducated NK cells is decreased signaling of activating receptors. The observation of decreased proximal signaling of activating receptors in uneducated $\mathrm{NK}$ cells has to date mostly been highlighted through calcium mobilization assays. ${ }^{46,50}$ In these studies, antibody-mediated cross-linking of the activating receptors in flow cytometry-based assays have provided insight that very early signaling events are disrupted in uneducated NK cells. It remains to be addressed as to the precise extent of these disrupted signaling pathways. For instance, is the hyporesponsiveness of uneducated NK cells due to decreased recruitment of signaling-related proteins to activating receptors, a failure of activating receptors to mobilize on the plasma membrane, or the product of activities similar to those observed with receptor desensitization?

\section{Education is maintained after cytokine priming}

Understanding NK cell education is difficult in that the most practical readout of education (ie, NK cell functionality) is regulated through several mechanisms that may be independent of one another. For instance, cytokine treatments or stimulations with materials such as the pattern recognition receptor ligand Poly I:C also enhance NK cell functionality but they have not been shown to "reverse" a lack of NK cell education. While it is true that cytokines such as IL-2, IL-15, or IL-12 and IL-18 enhance NK cell function, ${ }^{58-60}$ there is no evidence that these treatments undo the processes imparted by education. These cytokines promote both immediate and progressive alterations in NK cell biology to induce better activation. For instance, short-term treatment of NK cells with IL-2 promotes enhanced conjugation to target cells. ${ }^{61}$ Long-term treatment with IL-2 enables better calcium mobilization in all NK cells upon activation ${ }^{51}$ and eventual altered gene regulation in NK cells. ${ }^{62} \mathrm{NK}$ cell education does not affect basal gene transcription for enhanced function. ${ }^{50} \mathrm{With}$ prolonged treatment, it is likely that cytokines such as IL-2 or IL-15 could be altering education by inducing inhibitory receptor expression. ${ }^{27,37}$ In this manner, IL-2 or IL-15 could promote better education of NK cells through the principles of education. In terms of other types of stimulatory materials, Poly I:C actually further distinguishes educated NK cells from uneducated NK cells by enabling stronger NK cell responses from previously unstimulated mice ${ }^{19,21}$ in contrast to initial reports. ${ }^{13}$ Furthermore, Poly I:C primes NK cells indirectly through the transpresentation of IL-15 on activated dendritic cells (DC), ${ }^{60}$ thus connecting the two different stimulations for enhanced NK cell function. Similar to the idea regarding cytokine treatments, there may be misconceptions that strong responses through activating receptors such as those achieved through CD16 may overcome NK cell education deficiencies since uneducated NK cells can perform quite well in activities like $\mathrm{ADCC}^{52}$ and viral clearance. ${ }^{53}$ In fact, maximal ADCC responses requires NK cell education. ${ }^{63}$ Additionally, educated NK cells can better regulate anti-viral responses in the absence of influencing Tregs. ${ }^{54}$ Again, the deficiencies of uneducated NK cells may be masked by stronger responses through activating receptors with a given stimulation, but it is likely that the educated NK cell will respond better than the uneducated NK cell to the stimulation. In other words, the process of education is not reversible through strong stimulation. Thus far, it has been demonstrated that education can only be reversed through altered surrounding MHC class I and NK cell inhibitory interactions.

\section{Several inhibitory receptors promote education}

KIR expression alone does not guarantee that human NK cells become educated. As mentioned earlier in this review, other receptors such as NKG2A also factor into the education of 
NK cells. NKG2A is especially important in that its ligand HLA-E is more ubiquitously expressed than the major KIR ligand HLA-C. ${ }^{64,65}$ Furthermore, almost all CD56bright NK cells and often half or more CD56dim NK cells express NKG2A. ${ }^{66}$ Also, in situations of inflammation like those with production of IFN-gamma, HLA-E expression is elevated. ${ }^{67,68}$ Additionally, the nonconventional MHC class I molecule H2-M3 expressed on B cells also functions as an educating ligand of Ly49A+ NK cells in mice. ${ }^{69}$ It is possible that several other types of inhibitory receptor-ligand interactions will be discovered to have roles in NK cell education. Although it is not disputed among those that study NK cell education, it may be a misconception for some in the greater scientific community that the simple expression of any given KIR would guarantee better responsiveness through education. While perhaps informative when the particular HLA expression of an individual is unknown, qualifying an NK cell as educated simply based on the single expression of KIR2DL1, KIR2DL2, KIR2DL3, or KIR3DL1 alone is insufficient. KIR specifically recognize certain HLA molecule types ${ }^{2,32}$ and that recognition enables KIR-mediated education. KIR expression is stochastic, ${ }^{29-32}$ with some individuals completely lacking NK cells that express a particular KIR even though it may be an educating KIR on the basis of the individual's HLA type. ${ }^{33-36}$ Furthermore, it is likely that a substantial percentage of individuals have a majority of their NK cells lacking education obtained through KIR expression. ${ }^{70}$ A last comment concerning KIR and education, KIR can be activating in addition to inhibitory. ${ }^{71}$ In order to educate an NK cell, the KIR must be of the inhibitory variety. NK cells that express certain activating KIR, such as KIR2DS1, actually demonstrate less functionally in HLA-matching HLA-C type 2-carrying individuals despite also expressing the educating inhibitory KIR2DL1 compared to KIR2DS1-negative NK cell populations. ${ }^{72}$ It may be that KIR2DS1 in these HLA-C type 2-carrying individuals contributes in the disarming of NK cells that leads to their decreased responsiveness.

\section{Educated and uneducated NK cells may have separate and unique functions}

Finally, an intriguing idea is that uneducated NK cells could serve a totally different role in the immune system than educated NK cells. In particular, it is interesting to consider the potential differences between educated and uneducated NK cells in influencing the adaptive immune system. Murphy et al have reported for a role of uneducated NK cells in promoting the survival of DC through production of GM-CSF (Murphy et al, 2014, unpublished data). In turn, enhanced DC survival promotes better naïve $\mathrm{T}$ cell activation in the context of MCMV and influenza infections in mice as well as greater overall survival of the mice upon lethal re-challenges. By contrast, educated NK cells proactively kill newly activated $\mathrm{T}$ cells and thus negate the benefits of the adaptive response. Murphy et al further extended these results to human NK cells and found similar findings to what they observed from their mouse studies. This ability of educated NK cells to kill activated $T$ cells is in agreement with the emerging idea that NK cells can regulate the survival of $\mathrm{T}$ cells and, in turn, determine the outcome of diseases. ${ }^{73-75}$ Interestingly, activated educated NK cells can also aid DC maturation. ${ }^{76}$ Thus, educated and uneducated NK cells may have different roles in promoting the adaptive immune response.

\section{The application of NK cell education in anti-cancer immunotherapies}

There has already been substantial progress in the clinical application of NK cells in anti-cancer immunotherapies, despite only recent advancements toward understanding education. In general, NK cells have potent anti-tumor activities, especially with regard to leukemia. In a highly influential clinical study, T cell- depleted hematopoietic cell transplantation for treatment of myeloid leukemia displayed superior efficacy from donors who possessed NK cells that were mismatch with the recipients' HLA type. ${ }^{77}$ Several groups have made strides toward understanding the applicability of NK cells in cancer. It is highly recommended that their progress be read about in their thought provoking reviews. ${ }^{78-80}$

Since NK cell education is reversible, altering the education status of NK cells is an attractive option for anti-cancer immunotherapy. Currently, many anti-cancer immunotherapies target the cytolytic potential of NK cells through cytokine treatments or through antibody-mediated blockade of inhibitory receptors. While the use of mitogenic cytokines such as IL-2 or IL-15 does enhance the cytolytic potential of NK cells, these cytokines also induce changes in inhibitory receptor expression of both KIR and NKG2A. Equally as important as altered KIR expression is the acquired expression of NKG2A following cytokine treatment, which could have serious implications on the activity of the delivered NK cells. ${ }^{81}$ If the tumor that is being considered for clearance expresses HLA, it will most certainly also express the non-classical HLA as well. In terms of antibody-mediated alteration of NK cell functionality, there is currently an emphasis on disrupting KIR-mediated inhibition. Antibody-mediated blockade of inhibitory receptors like KIR2DL1/2/3 with human mAb $1-7 \mathrm{~F}^{82}$ is being 
investigated as an immunomodulator in cancer. ${ }^{83}$ The purpose of this blockade is to reduce conventional inhibition, but it is unknown how this treatment may affect education and result in decreased functionality over time. It is also interesting to consider increasing KIR or NKG2A expression on NK cells through mRNA transfection to potentially enable NK cells to become more educated. mRNA-transfection of NK cells is particularly intriguing because it is highly efficient in inducing the expression of the new proteins; varying the amount of mRNA delivered to cells results in precise expression of the protein. ${ }^{84}$ Furthermore, since there is no genetic manipulation, there is no concern that genetic information has integrated into the patient's genome. Ideally, transfection of NK cells to express a protein that is important in NK cell education (but not in conventional inhibition) would be ideal. Such a manipulation would allow for enhanced functionality without the drawbacks of potential inhibition. More basic science research is necessary to understand if such a protein (or other types of molecules) exists or could be modulated for immunotherapy.

There are several intriguing avenues to apply the principles of NK cell education in the development of anti-cancer therapies. The current application of NK cell harnesses the conventional cytolytic capacity of NK cells in killing tumor cells. Nevertheless, there is increasing evidence that NK cells can kill T cells, ${ }^{73-75}$ which may complicate immune responses to tumors. A comprehensive evaluation of this possibility is required in future studies. Furthermore, NK cell control of cancer appears to be best during the early stages of cancer cell neoplasia, prior to further tumor development and metastasis. ${ }^{85}$ While prophylactic intervention works to prevent tumor development in mouse models, the anti-tumor therapies for humans are often considered well after these early stages. Rather than relying on the cytolytic potential of NK cells in the direct control of tumor cells, it may be possible to harness the ability of NK cells to augment productive anti-tumor directed T cells. ${ }^{86,87} \mathrm{NK}$ cells can induce DC maturation, ${ }^{88-90}$ prime CD8+ T cells, ${ }^{91,92}$ and directly skew $\mathrm{T}$ helper cell differentiation to the IFN-gamma producing Th1 phenotype. ${ }^{93-96}$ Initiating and enhancing Th1 polarization and T cell-mediated cytotoxicity have proven efficacy in anti-tumor responses. Work from Murphy et al suggests that uneducated NK cells can also participate in the maintenance of the adaptive response. Additionally, since the tumor microenvironment is plagued with suppressive Tregs, and educated NK cells are more greatly affected by Tregs than uneducated NK cells, it is certainly possible to consider the role of uneducated NK cells in addition to educated NK cells.
Fundamental information about NK cell education is necessary for optimal immunotherapy. For starters, it is unknown how long education persists from the last inhibitory receptor and HLA interaction. Additionally, there is a need for more human studies to determine which cell types allow for productive HLA engagements with NK cell inhibitory receptors during education. Notably, these parameters may be different between hematopoietic cell transplantation and adoptive transfer of mature NK cells, due to differences in location and timing. Understanding the steps required for the re-education of NK cells will provide for better anti-cancer immunotherapies.

\section{Conclusion}

The future of NK cell research is wide-open and promising. Understanding the complexity of these cells and their relevance in immunotherapies is pertinent to improving human health. Harnessing the capabilities of NK cells to become more or less responsive, and to function in different activities to augment the immune response is at the forefront. Nevertheless, there are also gains to be made from studying the basic science of NK cells, including NK cell education. For instance, the exact mechanism behind NK cell education remains to be determined but is of importance to fully exploit the anti-tumor potential of NK cells. Additionally, the identities of the ligands responsible for some critical activating receptors of $\mathrm{NK}$ cells are disputed whereas others still remain a mystery. Lastly, there needs to be a better understanding of how inhibitory receptors like KIR signal in both conventional inhibition and in education. For instance, what are the related signaling proteins associated with their function? Are these proteins the same between inhibition of immune synapse formation during activation and those necessary to promote education? It is also intriguing to consider the antigen-specific memory ${ }^{97,98}$ and adaptive-like ${ }^{99,100}$ capabilities of NK cells in concert with education to better NK cell therapies. A better understanding of the fundamentals of NK cell biology will surely promote better immunotherapies in cancer.

\section{Acknowledgment}

The author will like to thank Laura E Kropp for proofreading this manuscript.

\section{Disclosure}

The author reports no conflicts of interest in this work.

\section{References}

1. Long EO, Kim HS, Liu D, Peterson ME, Rajagopalan S. Controlling natural killer cell responses: integration of signals for activation and inhibition. Annu Rev Immunol. 2013;31:227-258. 
2. Vilches C, Parham P. KIR: diverse, rapidly evolving receptors of innate and adaptive immunity. Аnпи Rev Immunol. 2002;20:217-251.

3. Burshtyn DN, Scharenberg AM, Wagtmann N, et al. Recruitment of tyrosine phosphatase HCP by the killer cell inhibitor receptor. Immunity. 1996;4(1):77-85.

4. Campbell KS, Dessing M, Lopez-Botet M, Cella M, Colonna M. Tyrosine phosphorylation of a human killer inhibitory receptor recruits protein tyrosine phosphatase 1C. J Exp Med. 1996;184(1): 93-100.

5. Fry AM, Lanier LL, Weiss A. Phosphotyrosines in the killer cell inhibitory receptor motif of NKB1 are required for negative signaling and for association with protein tyrosine phosphatase 1C. J Exp Med. 1996;184(1):295-300.

6. Olcese L, Lang P, Vely F, et al. Human and mouse killer-cell inhibitory receptors recruit PTP1C and PTP1D protein tyrosine phosphatases. J Immunol. 1996;156(12):4531-4534.

7. Peterson ME, Long EO. Inhibitory receptor signaling via tyrosine phosphorylation of the adaptor Crk. Immunity. 2008;29(4):578-588.

8. Stebbins CC, Watzl C, Billadeau DD, Leibson PJ, Burshtyn DN, Long EO. Vav1 dephosphorylation by the tyrosine phosphatase SHP-1 as a mechanism for inhibition of cellular cytotoxicity. Mol Cell Biol. 2003;23(17):6291-6299.

9. Mesecke S, Urlaub D, Busch H, Eils R, Watzl C. Integration of activating and inhibitory receptor signaling by regulated phosphorylation of Vav1 in immune cells. Sci Signal. 2011;4(175):ra36.

10. Liu D, Peterson ME, Long EO. The adaptor protein Crk controls activation and inhibition of natural killer cells. Immunity. 2012;36(4): 600-611.

11. Liu D. The adaptor protein Crk in immune response. Immunol Cell Biol. 2014;92(1):80-89.

12. Anfossi N, Andre P, Guia S, et al. Human NK cell education by inhibitory receptors for MHC class I. Immunity. 2006;25(2):331-342.

13. Kim S, Poursine-Laurent J, Truscott SM, et al. Licensing of natural killer cells by host major histocompatibility complex class I molecules. Nature. 2005;436(7051):709-713.

14. Elliott JM, Yokoyama WM. Unifying concepts of MHC-dependent natural killer cell education. Trends Immunol. 2011;32(8):364-372.

15. Bix M, Liao NS, Zijlstra M, Loring J, Jaenisch R, Raulet D. Rejection of class I MHC-deficient haemopoietic cells by irradiated MHC-matched mice. Nature. 1991;349(6307):329-331.

16. Hoglund P, Ohlen C, Carbone E, et al. Recognition of beta 2-microglobulin-negative (beta $2 \mathrm{~m}$-) T-cell blasts by natural killer cells from normal but not from beta $2 \mathrm{~m}$ - mice: nonresponsiveness controlled by beta $2 \mathrm{~m}$ - bone marrow in chimeric mice. Proc Natl Acad Sci U SA 1991;88(22):10332-10336.

17. Liao NS, Bix M, Zijlstra M, Jaenisch R, Raulet D. MHC class I deficiency: susceptibility to natural killer (NK) cells and impaired NK activity. Science. 1991;253(5016):199-202.

18. Ohlen C, Hoglund P, Sentman CL, et al. Inhibition of natural killer cell-mediated bone marrow graft rejection by allogeneic major histocompatibility complex class I, but not class II molecules. Eur J Immunol. 1995;25(5):1286-1291.

19. Brodin P, Lakshmikanth T, Johansson S, Karre K, Hoglund P. The strength of inhibitory input during education quantitatively tunes the functional responsiveness of individual natural killer cells. Blood. 2009;113(11):2434-2441.

20. Johansson S, Johansson M, Rosmaraki E, et al. Natural killer cell education in mice with single or multiple major histocompatibility complex class I molecules. J Exp Med. 2005;201(7): $1145-1155$.

21. Joncker NT, Fernandez NC, Treiner E, Vivier E, Raulet DH. NK cell responsiveness is tuned commensurate with the number of inhibitory receptors for self-MHC class I: the rheostat model. J Immunol. 2009;182(8):4572-4580.

22. Jonsson AH, Yang L, Kim S, Taffner SM, Yokoyama WM. Effects of MHC class I alleles on licensing of Ly49A+ NK cells. J Immunol. 2010;184(7):3424-3432.
23. Elliott JM, Wahle JA, Yokoyama WM. MHC class I-deficient natural killer cells acquire a licensed phenotype after transfer into an MHC class I-sufficient environment. $J$ Exp Med. 2010;207(10): 2073-2079.

24. Joncker NT, Shifrin N, Delebecque F, Raulet DH. Mature natural killer cells reset their responsiveness when exposed to an altered MHC environment. J Exp Med. 2010;207(10):2065-2072.

25. Beziat V, Descours B, Parizot C, Debre P, Vieillard V. NK cell terminal differentiation: correlated stepwise decrease of NKG2A and acquisition of KIRs. PLoS One. 2010;5(8):e11966.

26. Bjorkstrom NK, Riese P, Heuts F, et al. Expression patterns of NKG2A, KIR, and CD57 define a process of CD56dim NK-cell differentiation uncoupled from NK-cell education. Blood. 2010;116(19): 3853-3864.

27. Romagnani C, Juelke K, Falco M, et al. CD56brightCD16- killer Iglike receptor- NK cells display longer telomeres and acquire features of CD56dim NK cells upon activation. J Immunol. 2007;178(8): 4947-4955.

28. Yu J, Freud AG, Caligiuri MA. Location and cellular stages of natural killer cell development. Trends Immunol. 2013;34(12):573-582.

29. Litwin V, Gumperz J, Parham P, Phillips JH, Lanier LL. Specificity of HLA class I antigen recognition by human NK clones: evidence for clonal heterogeneity, protection by self and non-self alleles, and influence of the target cell type. $J$ Exp Med. 1993;178(4):1321-1336.

30. Moretta A, Bottino C, Pende D, et al. Identification of four subsets of human CD3-CD16+ natural killer (NK) cells by the expression of clonally distributed functional surface molecules: correlation between subset assignment of NK clones and ability to mediate specific alloantigen recognition. J Exp Med. 1990;172(6):1589-1598.

31. Moretta A, Tambussi G, Bottino C, et al. A novel surface antigen expressed by a subset of human CD3-CD16+ natural killer cells. Role in cell activation and regulation of cytolytic function. $J$ Exp Med. 1990;171(3):695-714.

32. Valiante NM, Uhrberg M, Shilling HG, et al. Functionally and structurally distinct NK cell receptor repertoires in the peripheral blood of two human donors. Immunity. 1997;7(6):739-751.

33. Andersson S, Fauriat C, Malmberg JA, Ljunggren HG, Malmberg KJ. KIR acquisition probabilities are independent of self-HLA class I ligands and increase with cellular KIR expression. Blood. 2009;114(1): 95-104.

34. Beziat V, Traherne JA, Liu LL, et al. Influence of KIR gene copy number on natural killer cell education. Blood. 2013;121(23):4703-4707.

35. Li H, Pascal V, Martin MP, Carrington M, Anderson SK. Genetic control of variegated KIR gene expression: polymorphisms of the bi-directional KIR3DL1 promoter are associated with distinct frequencies of gene expression. PLoS Genet. 2008;4(11):e1000254.

36. Yawata M, Yawata N, Draghi M, Partheniou F, Little AM, Parham P. MHC class I-specific inhibitory receptors and their ligands structure diverse human NK-cell repertoires toward a balance of missing self-response. Blood. 2008;112(6):2369-2380.

37. Cooley S, Xiao F, Pitt M, et al. A subpopulation of human peripheral blood NK cells that lacks inhibitory receptors for self-MHC is developmentally immature. Blood. 2007;110(2):578-586.

38. Juelke K, Killig M, Thiel A, Dong J, Romagnani C. Education of hyporesponsive NK cells by cytokines. Eur J Immunol. 2009;39(9): 2548-2555.

39. Ardolino M, Azimi CS, Iannello A, et al. Cytokine therapy reverses NK cell anergy in MHC-deficient tumors. J Clin Invest. 2014;124(11): 4781-4794.

40. Rock KL, Goldberg AL. Degradation of cell proteins and the generation of MHC class I-presented peptides. Annu Rev Immunol. 1999;17: 739-779.

41. Hoglund P, Brodin P. Current perspectives of natural killer cell education by MHC class I molecules. Nat Rev Immunol. 2010;10(10):724-734.

42. Oppenheim DE, Roberts SJ, Clarke SL, et al. Sustained localized expression of ligand for the activating NKG2D receptor impairs natural cytotoxicity in vivo and reduces tumor immunosurveillance. Nat Immunol. 2005;6(9):928-937. 
43. Sun JC, Lanier LL. Tolerance of NK cells encountering their viral ligand during development. J Exp Med. 2008;205(8):1819-1828.

44. Tripathy SK, Keyel PA, Yang L, et al. Continuous engagement of a self-specific activation receptor induces NK cell tolerance. $J$ Exp Med. 2008;205(8):1829-1841.

45. Champsaur M, Beilke JN, Ogasawara K, Koszinowski UH, Jonjic S, Lanier LL. Intact NKG2D-independent function of NK cells chronically stimulated with the NKG2D ligand Rae-1. J Immunol. 2010;185(1): $157-165$.

46. Viant C, Fenis A, Chicanne G, Payrastre B, Ugolini S, Vivier E. SHP-1-mediated inhibitory signals promote responsiveness and antitumour functions of natural killer cells. Nat Commun. 2014;5:5108.

47. Shifrin N, Raulet DH, Ardolino M. NK cell self tolerance, responsiveness and missing self recognition. Semin Immunol. 2014;26(2):138-144.

48. Bessoles S, Grandclement C, Alari-Pahissa E, Gehrig J, Jeevan-Raj B, Held W. Adaptations of natural killer cells to self-MHC class I. Front Immunol. 2014;5:349.

49. Chalifour A, Scarpellino L, Back J, et al. A Role for cis Interaction between the Inhibitory Ly49A receptor and MHC class I for natural killer cell education. Immunity. 2009;30(3):337-347.

50. Guia S, Jaeger BN, Piatek S, et al. Confinement of activating receptors at the plasma membrane controls natural killer cell tolerance. Sci Signal. 2011;4(167):ra21

51. Bryceson YT, March ME, Ljunggren HG, Long EO. Synergy among receptors on resting NK cells for the activation of natural cytotoxicity and cytokine secretion. Blood. 2006;107(1):159-166.

52. Tarek N, Le Luduec JB, Gallagher MM, et al. Unlicensed NK cells target neuroblastoma following anti-GD2 antibody treatment. $J$ Clin Invest. 2012;122(9):3260-3270.

53. Orr MT, Murphy WJ, Lanier LL. 'Unlicensed' natural killer cells dominate the response to cytomegalovirus infection. Nat Immunol. 2010;11(4):321-327.

54. Sungur CM, Tang-Feldman YJ, Ames E, et al. Murine natural killer cell licensing and regulation by $\mathrm{T}$ regulatory cells in viral responses. Proc Natl Acad Sci U S A. 2013;110(18):7401-7406.

55. Mace EM, Dongre P, Hsu HT, et al. Cell biological steps and checkpoints in accessing NK cell cytotoxicity. Immunol Cell Biol. 2014;92(3):245-255.

56. Zhang M, March ME, Lane WS, Long EO. A signaling network stimulated by beta2 integrin promotes the polarization of lytic granules in cytotoxic cells. Sci Signal. 2014;7(346):ra96.

57. Thomas LM, Peterson ME, Long EO. Cutting edge: NK cell licensing modulates adhesion to target cells. J Immunol. 2013;191(8):3981-3985.

58. Chaix J, Tessmer MS, Hoebe K, et al. Cutting edge: Priming of NK cells by IL-18. J Immunol. 2008;181(3):1627-1631.

59. Fehniger TA, Cai SF, Cao X, et al. Acquisition of murine NK cell cytotoxicity requires the translation of a pre-existing pool of granzyme B and perforin mRNAs. Immunity. 2007;26(6):798-811.

60. Lucas M, Schachterle W, Oberle K, Aichele P, Diefenbach A. Dendritic cells prime natural killer cells by trans-presenting interleukin 15 . Immunity. 2007;26(4):503-517.

61. Gasteiger G, Hemmers S, Firth MA, et al. IL-2-dependent tuning of NK cell sensitivity for target cells is controlled by regulatory T cells. $J$ Exp Med. 2013;210(6):1167-1178.

62. Dybkaer K, Iqbal J, Zhou G, et al. Genome wide transcriptional analysis of resting and IL2 activated human natural killer cells: gene expression signatures indicative of novel molecular signaling pathways. $B M C$ Genomics. 2007;8:230.

63. Parsons MS, Zipperlen K, Gallant M, Grant M. Killer cell immunoglobulin-like receptor 3DL1 licenses CD16-mediated effector functions of natural killer cells. J Leukoc Biol. 2010;88(5):905-912.

64. Lee N, Llano M, Carretero M, et al. HLA-E is a major ligand for the natural killer inhibitory receptor CD94/NKG2A. Proc Natl Acad Sci USA. 1998;95(9):5199-5204.

65. Sullivan LC, Clements CS, Rossjohn J, Brooks AG. The major histocompatibility complex class Ib molecule HLA-E at the interface between innate and adaptive immunity. Tissue Antigens. 2008;72(5): 415-424.
66. Andre P, Spertini O, Guia S, et al. Modification of P-selectin glycoprotein ligand-1 with a natural killer cell-restricted sulfated lactosamine creates an alternate ligand for L-selectin. Proc Natl Acad Sci U S A. 2000;97(7):3400-3405.

67. Malmberg KJ, Levitsky V, Norell H, et al. IFN-gamma protects shortterm ovarian carcinoma cell lines from CTL lysis via a CD94/NKG2Adependent mechanism. $J$ Clin Invest. 2002;110(10):1515-1523.

68. Vance RE, Kraft JR, Altman JD, Jensen PE, Raulet DH. Mouse CD94/ $\mathrm{NKG} 2 \mathrm{~A}$ is a natural killer cell receptor for the nonclassical major histocompatibility complex (MHC) class I molecule Qa-1(b). J Exp Med. 1998;188(10): 1841-1848

69. Andrews DM, Sullivan LC, Baschuk N, et al. Recognition of the nonclassical MHC class I molecule H2-M3 by the receptor Ly49A regulates the licensing and activation of NK cells. Nat Immunol. 2012;13(12): 1171-1177.

70. Fauriat C, Andersson S, Bjorklund AT, et al. Estimation of the size of the alloreactive NK cell repertoire: studies in individuals homozygous for the group A KIR haplotype. J Immunol. 2008;181(9):6010-6019.

71. Moesta AK, Parham P. Diverse functionality among human NK cell receptors for the $\mathrm{C} 1$ epitope of HLA-C: KIR2DS2, KIR2DL2, and KIR2DL3. Front Immunol. 2012;3:336.

72. Fauriat C, Ivarsson MA, Ljunggren HG, Malmberg KJ, Michaelsson J. Education of human natural killer cells by activating killer cell immunoglobulin-like receptors. Blood. 2010;115(6):1166-1174.

73. Peppa D, Gill US, Reynolds G, et al. Up-regulation of a death receptor renders antiviral $\mathrm{T}$ cells susceptible to NK cell-mediated deletion. J Exp Med. 2013;210(1):99-114.

74. Waggoner SN, Cornberg M, Selin LK, Welsh RM. Natural killer cells act as rheostats modulating antiviral T cells. Nature. 2011;481(7381): 394-398.

75. Waggoner SN, Taniguchi RT, Mathew PA, Kumar V, Welsh RM. Absence of mouse 2B4 promotes NK cell-mediated killing of activated CD8+ T cells, leading to prolonged viral persistence and altered pathogenesis. J Clin Invest. 2010;120(6):1925-1938.

76. Holmes TD, Wilson EB, Black EV, et al. Licensed human natural killer cells aid dendritic cell maturation via TNFSF14/LIGHT. Proc Natl Acad Sci U S A. 2014;111(52):E5688-E5696.

77. Ruggeri L, Capanni M, Urbani E, et al. Effectiveness of donor natural killer cell alloreactivity in mismatched hematopoietic transplants. Science. 2002;295(5562):2097-2100.

78. Locatelli F, Pende D, Mingari MC, et al. Cellular and molecular basis of haploidentical hematopoietic stem cell transplantation in the successful treatment of high-risk leukemias: role of alloreactive NK cells. Front Immunol. 2013;4:15.

79. Murphy WJ, Parham P, Miller JS. NK cells - from bench to clinic. Biol Blood Marrow Transplant. 2012;18(1 Suppl):S2-S7.

80. Norell H, Moretta A, Silva-Santos B, Moretta L. At the Bench: Preclinical rationale for exploiting NK cells and gammadelta $T$ lymphocytes for the treatment of high-risk leukemias. J Leukoc Biol. 2013;94(6):1123-1139.

81. Godal R, Bachanova V, Gleason M, et al. Natural killer cell killing of acute myelogenous leukemia and acute lymphoblastic leukemia blasts by killer cell immunoglobulin-like receptor-negative natural killer cells after NKG2A and LIR-1 blockade. Biol Blood Marrow Transplant. 2010;16(5):612-621.

82. Romagne F, Andre P, Spee P, et al. Preclinical characterization of 1-7F9, a novel human anti-KIR receptor therapeutic antibody that augments natural killer-mediated killing of tumor cells. Blood. 2009;114(13): 2667-2677.

83. Thielens A, Vivier E, Romagne F. NK cell MHC class I specific receptors (KIR): from biology to clinical intervention. Curr Opin Immunol. 2012;24(2):239-245.

84. Li L, Liu LN, Feller S, et al. Expression of chimeric antigen receptors in natural killer cells with a regulatory-compliant non-viral method. Cancer Gene Ther. 2010;17(3):147-154.

85. Raulet DH, Guerra N. Oncogenic stress sensed by the immune system: role of natural killer cell receptors. Nat Rev Immunol. 2009;9(8): $568-580$. 
86. Fan Z, Yu P, Wang Y, et al. NK-cell activation by LIGHT triggers tumor-specific CD8+ T-cell immunity to reject established tumors. Blood. 2006;107(4):1342-1351.

87. Kelly JM, Darcy PK, Markby JL, et al. Induction of tumor-specific $\mathrm{T}$ cell memory by NK cell-mediated tumor rejection. Nat Immunol. 2002;3(1):83-90.

88. Gerosa F, Baldani-Guerra B, Nisii C, Marchesini V, Carra G, Trinchieri G. Reciprocal activating interaction between natural killer cells and dendritic cells. J Exp Med. 2002;195(3):327-333.

89. Piccioli D, Sbrana S, Melandri E, Valiante NM. Contact-dependent stimulation and inhibition of dendritic cells by natural killer cells. J Exp Med. 2002;195(3):335-341.

90. Vitale M, Della Chiesa M, Carlomagno S, et al. NK-dependent DC maturation is mediated by TNFalpha and IFNgamma released upon engagement of the NKp30 triggering receptor. Blood. 2005;106(2):566-571.

91. Krebs P, Barnes MJ, Lampe K, et al. NK-cell-mediated killing of target cells triggers robust antigen-specific T-cell-mediated and humoral responses. Blood. 2009;113(26):6593-6602.

92. Mocikat R, Braumuller H, Gumy A, et al. Natural killer cells activated by MHC class I (low) targets prime dendritic cells to induce protective CD8 T cell responses. Immunity. 2003;19(4):561-569.
93. Bajenoff M, Breart B, Huang AY, et al. Natural killer cell behavior in lymph nodes revealed by static and real-time imaging. J Exp Med. 2006;203(3):619-631.

94. LaouarY, Sutterwala FS, Gorelik L, Flavell RA. Transforming growth factor-beta controls $\mathrm{T}$ helper type 1 cell development through regulation of natural killer cell interferon-gamma. Nat Immunol. 2005;6(6): 600-607.

95. Martin-Fontecha A, Thomsen LL, Brett S, et al. Induced recruitment of NK cells to lymph nodes provides IFN-gamma for $\mathrm{T}(\mathrm{H}) 1$ priming Nat Immunol. 2004;5(12):1260-1265.

96. Morandi B, Bougras G, Muller WA, Ferlazzo G, Munz C. NK cells of human secondary lymphoid tissues enhance $\mathrm{T}$ cell polarization via IFN-gamma secretion. Eur J Immunol. 2006;36(9):2394-2400.

97. Jiang X, Chen Y, Peng H, Tian Z. Memory NK cells: why do they reside in the liver? Cell Mol Immunol. 2013;10(3):196-201.

98. Paust S, von Andrian UH. Natural killer cell memory. Nat Immunol. 2011;12(6):500-508.

99. Cooper MA, Yokoyama WM. Memory-like responses of natural killer cells. Immunol Rev. 2010;235(1):297-305.

100. Sun JC, Lopez-Verges S, Kim CC, DeRisi JL, Lanier LL. NK cells and immune "memory". J Immunol. 2011;186(4):1891-1897.

\section{Publish your work in this journal}

ImmunoTargets and Therapy is an international, peer-reviewed open access journal focusing on the immunological basis of diseases, potential targets for immune based therapy and treatment protocols employed to improve patient management. Basic immunology and physiology of the immune system in health, and disease will be also covered. In addition, the journal will focus on the impact of manage-

\section{Dovepress}

ment programs and new therapeutic agents and protocols on patient perspectives such as quality of life, adherence and satisfaction. The manuscript management system is completely online and includes a very quick and fair peer-review system, which is all easy to use. Visit http://www.dovepress.com/testimonials.php to read real quotes from published authors.

Submit your manuscript here: http://www.dovepress.com/immunotargets-and-therapy-journal 